\title{
A cross-sectional study of the prevalence, density and risk factors associated with malaria transmission in urban communities of Ibadan, Southwestern Nigeria
}

Oluwaseun Awosolu ( $\nabla$ obawosolu@student.usm.my )

Universiti Sains Malaysia - Kampus Kesihatan https://orcid.org/0000-0002-5213-7397

Zary Shariman Yahaya

Universiti Sains Malaysia, Malaysia

Farah Haziqah Meor Termizi

Universiti Sains Malaysia - Kampus Kesihatan

lyabo Adepeju Simon-Oke

Federal University of Technology Akure

Comfort Fakunle

Federal University of Technology Akure

\section{Research Article}

Keywords: Ibadan, malaria infection, Plasmodium falciparum, prevalence, risk factors, rural-urban areas

Posted Date: September 15th, 2020

DOI: https://doi.org/10.21203/rs.3.rs-74176/v1

License: (c) (i) This work is licensed under a Creative Commons Attribution 4.0 International License. Read Full License

Version of Record: A version of this preprint was published at Heliyon on January 1st, 2021. See the published version at https://doi.org/10.1016/j.heliyon.2021.e05975. 


\section{Abstract \\ Background}

Malaria is a serious global public health challenge which causes great morbidity and mortality worldwide particularly in subSaharan Africa. This study was designed to determine the prevalence, parasite density and risk factors associated with malaria infection transmission among residents of two urban communities of Ibadan, southwestern Nigeria.

\section{Methods}

A cross-sectional hospital-based study was carried out on 300 participants. Blood samples were obtained. Thick and thin blood films were prepared and viewed using the standard parasitological technique of microscopy. Moreover, data on sociodemographic and environmental variables were obtained using standard questionnaire.

\section{Results}

Of the 300 participants examined, a total of 165 (55.0\%) were found positive for Plasmodium falciparum with a mean (S.D) parasite density of 1814.70 (1829.117) parasite/ $\mu \mathrm{L}$ of blood. The prevalence and parasite density of malaria infection was statistically significant $(P<0.05)$ in relation to age group. Obviously, malaria infection decreases as age increasing with $\leq$ 5 years having the highest prevalence and mean parasite density. Similarly, in relation to gender, males significantly $(P<0.05)$ had higher prevalence (60.2\%) and mean (S.D) parasite density of malaria infection [2157.73 (1659.570) parasite/ $\mu \mathrm{L}$ of blood] compared to females. Additionally, those without formal education had the highest prevalence (73.0\%) and mean (S.D) parasite density of infection [2626.96 (2442.195) parasite/ $\mu \mathrm{L}$ of blood]. The binary logistic regression analysis showed that age group 6-10 (COR 0.066, 95\% Cl: 0.007-0.635), presence of streams (COR 0.225, 95\% Cl: 0.103-0.492), distance from streams within $\leq 1 \mathrm{Km}(\mathrm{COR} 0.283,95 \% \mathrm{Cl}: 0.122-0.654)$ and travel to rural area (COR 4.689, 95\% Cl: $2.430-9.049)$ were the major risk factors.

\section{Conclusions}

Malaria infection is apparently endemic in the study area and greatly influenced by rural-urban movement. Multifaceted and integrated control strategy should be adopted. Health education on mosquito prevention and use of chemoprophylaxis before and during travel to rural areas are important.

\section{Background}

Malaria is an important public health disease caused by Plasmodium parasite belonging to the Apicomplexans [1]. It is spread when an infected female Anopheles mosquito feeds on blood meal from man [2]. It is majorly infecting people in the tropical and subtropical countries of the world particularly in sub-Saharan Africa [3]. The four major malaria parasite causing disease in humans include $P$. falciparum, $P$. vivax, $P$. malariae and $P$. ovale while $P$. knowlesi is a zoonotic species found in Southeast Asia [4]. P. falciparum is considered the most pathogenic of all and it is the most prevalent in Africa $[5,6]$. Though, malaria is a curable and preventable disease, it is saddening that malaria persists to have an overwhelming impact on people's health across the world particularly among pregnant women and children in rural and urban areas [3]. Globally, it is estimated that 3.2 billion people are predisposed to contracting malaria disease annually [1]. Furthermore, about 219 million cases leading to approximately 435,000 deaths were reported in 2017 [3]. In Nigeria, malaria is transmitted throughout the year with more than $97 \%$ of Nigerians predisposed to contracting malaria infection. Thus, Nigeria reported the highest malaria prevalence among all countries of the world [7]. This have led to increased level of poverty as a result of unexpected expenses on treatment, control and prevention. Moreover, time expected to be at work and school are wasted on ill-health due to malaria infection thereby further aggravating the poor condition both in rural and urban areas [8]. 
Major risk factors enhancing the transmission of malaria infection include demographic factors such as age and gender, environmental factors such as presence or absence of bushes and forests which enhance mosquito breeding, climatic factors including temperature, humidity and rainfall that may support rapid growth and development of mosquito vectors, and socioeconomic factors such as education, occupation and income which directly affect human exposure and treatment pattern. All these factors have been well reported particularly in rural and peri-urban communities in previous studies [9]. Other studies have compared malaria parasite prevalence in rural and urban areas [10]. Despite better conditions in urban areas, studies have shown malaria parasites to be prevalence in urban areas [11,12]. Meanwhile, major factors enhancing malaria infections in these urban areas are yet to be fully unraveled. Thus, in order to align with the target to reduce malaria parasite by $90 \%$ between 2016 and 2030 by World Health Organization's Global Technical Strategy for malaria, there is need to understand and document adequate epidemiological data upon which malaria management and control could be based particularly in urban settings. Thus, this study sought to investigate the prevalence and risk factors enhancing the transmission of malaria parasites in two urban areas in Ibadan, Oyo State, Nigeria.

\section{Methods}

\section{Study area}

The study was carried out in Adeoyo State Hospital, Adegbite and Oni Memorial Children's Hospital, Ring-Road. Both hospitals are in Ibadan South West Local Government Area of Oyo State, Nigeria. Ibadan South West Local Government Area is situated between Latitude $7^{\circ} 21^{\prime} 2.48$ "N and Longitude $3^{\circ} 51^{\prime} 55.84$ "E (Fig. 1) and has a population of 282,585 as at 2006 census. Generally, Ibadan city is the third most populous city in Nigeria with over six million people. The climatic condition is typical of tropical regions which consists of both raining and dry seasons that spans through April to October and November to March respectively. The average annual rainfall is about $2100 \mathrm{~mm}$ while the temperature is about $27^{\circ} \mathrm{C}$. There are rivers running through the city of Ibadan which include Ogunpa, Kudeti and Ona river among others. The population consist of civil servants, traders, students, artisans and even farmers. While some of the residents live and settle in urban City of Ibadan, they still visit rural areas or their home village for some activities. Also, many people come from rural areas to Ibadan thereby hosting different people from various parts of the country. Nonetheless, Ibadan residents are predominantly of Yoruba ethnic group.

\section{Study design}

This is a hospital-based and randomized cross-sectional survey. Study was conducted from May to August 2019 in two different hospitals which are Adeoyo State Hospital, Adegbite and Oni Memorial Children's Hospital, Ring-Road, Ibadan. Samples were collected from individuals attending these hospitals and met the inclusion criteria. Criteria for inclusion include feelings of headache, fever with temperature greater than $38^{\circ} \mathrm{C}$, completion of questionnaires, blood samples submission and willingness to provide written or oral informed consent. Those who decline to participate were excluded. Questionnaire was given to each subject to collect their data such as age, sex, occupation, education, use of mosquito nets, presence or absence of river within $\leq 1 \mathrm{Km}$ participant's home. Other data such as blood group and genotype were gotten from their medical records.

\section{Sample size}

The sample size was computed using a previous malaria parasite prevalence of $78 \%$ [13] at a confidence interval (Cl) of $95 \%$ and $5 \%$ margin of error following the formula of Araoye, 2014 for calculating sample size. This give rise to a total of 300 subjects that were recruited for this study.

\section{Blood Collection and laboratory procedures}

Samples of blood were obtained intravenously with the assistance of a trained Laboratory Technologist. A $3 \mathrm{~mL}$ blood was obtained from each participant. After collection, blood samples were transferred into an ethylenediaminetetraacetic acid (EDTA) tube to prevent the coagulation of blood. Next, thick and thin smears were made on a well cleaned and sterilized slides. The thin smear was fixed in absolute ethanol. Subsequently, $3 \%$ stain made of Giemsa was added to the thick and thin smears for 30 minutes. The slides were later viewed under $x 100$ objective lens of the light microscope to confirm the presence or absence of 
Plasmodium parasites and the species present. When about 200 microscopic fields have been observed and no parasite discovered, it is considered negative. The mean parasite density was classified according to the recommendations of Atroosh et al. [14]. Parasite density was recorded as number of Parasite/ $\mu \mathrm{L}$ of blood, assuming an average leucocyte count of $8,000 / \mu \mathrm{L}$ of blood for an average individual [1]. The formula used is stated below

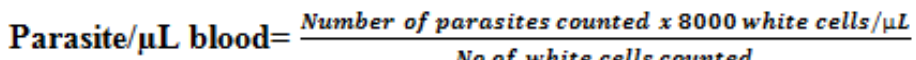 \\ No.of white cells counted}

\section{Statistical analysis}

Data collected were analyzed using SPSS version 20.0. The presence or absence of malaria parasite was computed and the differences in prevalence between age groups and sex were calculated using chi square test at $95 \%$ level of confidence. The malaria parasite density was computed using the student's t-test for dichotomous variable while ANOVA was used to determine categorical variables. Malaria-associated risk factor were determined by Bivariate logistic model. $P$-values of $\leq 0.05$ were recognized as significant.

\section{Ethical approval}

The protocol for this study was approved by Ondo State Ministry of Health (protocol number OSHREC/09/04/2018/046) the Ethical Review Committee, Federal University of Technology, Akure, Nigeria. Informed consent that were written were obtained from each adult subject. However, for children, their caregiver or guardians provided the informed consent.

\section{Results}

Of the total of 300 individuals that were selected for this study, males were $44.3 \%$ while females were $55.7 \%$. The age range was 1-65 years while the median age was 26 years. The mean (S.D) age was 28.03 (17.52). Furthermore, the individuals examined in Adeoyo State hospital and Oni Memorial hospital were 196 (65.3\%) and 104 (34.7\%) respectively (Table 1). All malaria infections in this study area was observed to be caused by P. falciparum and most (56.4\%) of the malaria infections were classified as low (< 1000 parasites/ $\mu \mathrm{L}$ of blood) while $43.6 \%$ were classified as moderate infections which ranges between 1000 to $\leq 9999$ parasites/ $\mu \mathrm{L}$ of blood.

In all, a total of $165(55.0 \%)$ had malaria infection with mean (S.D) parasite density of 1814.70 (1829.117) parasite/ $\mu \mathrm{L}$ of blood. The association between prevalence and density of $P$. falciparum and sociodemographic factors were presented in Table 1 . Age group $\leq 5$ years had the highest malaria prevalence of $76.7 \%$ while the lowest malaria prevalence of $43.2 \%$ was noted among the 31-40 years. Generally, malaria infection in this study decreases with increasing age and cumulate at age 40years (Table 1). There was significant difference $(P<0.05)$. Also, the highest mean (S.D) parasite density of infection was recorded among $\leq 5$ years [2433.43 (2547.742) parasite/ $\mu \mathrm{L}$ of blood] while the least was recorded among $>50$ [ $956.42(1262.708)$ parasite/ $\mu \mathrm{L}$ of blood]. There was no significant difference $(P>0.05)$.

In relation to gender, males had higher prevalence (60.2\%) and mean (S.D) parasite density of infection[2157.73 (1659.570) parasite/ $\mu \mathrm{L}$ of blood] compared to their female counterparts with malaria prevalence of $50.9 \%$ and mean (S.D) parasite density of 1491.85 (209.320) parasite/ $\mu \mathrm{L}$ of blood. Infection was significant at $P<0.05$.

Furthermore, those without formal education had infection that almost doubled those who attained tertiary education $(P<0.05)$. Similarly travelling to rural area or village highly contributed to malaria prevalence and parasite density. Those who travel to rural area or village significantly $(P<0.05)$ had higher malaria prevalence of $74.4 \%$ and mean (S.D) parasite density of 2367.51 (2098.600) parasite/ $\mu \mathrm{L}$ of blood compared to those who did not travel to rural area or village in the previous month (Table 1).

Table 1: Prevalence and density of Plasmodium falciparum infection stratified by sociodemographic variables 


\begin{tabular}{|c|c|c|c|}
\hline Variables & Number of subjects & Number positive (\%) & Mean ( \pm S.D) Parasite Density (parasite/ $\mu \mathrm{L}$ of blood) \\
\hline \multicolumn{4}{|l|}{ Age group } \\
\hline$\leq 5$ & 30 & $23(76.7)$ & $2433.43(2547.742)$ \\
\hline $6-10$ & 31 & $22(71.0)$ & $2211.45(1623.279)$ \\
\hline $11-20$ & 49 & $26(53.1)$ & $1478.00(1498.845) 1$ \\
\hline
\end{tabular}




\begin{tabular}{|c|c|c|c|}
\hline $21-30$ & 62 & $32(51.6)$ & $2327.03(2156.780)$ \\
\hline $31-40$ & 44 & $19(43.2)$ & $1527.11(1330.635)$ \\
\hline $41-50$ & 42 & $19(45.2)$ & 1575.89 (1447.093) \\
\hline$>50$ & 42 & $24(57.1)$ & $956.42(1262.708)$ \\
\hline$P$ value & & 0.03 & 0.38 \\
\hline \multicolumn{4}{|l|}{ Gender } \\
\hline Male & 133 & $80(60.2)$ & 2157.73 (1659.570) \\
\hline Female & 167 & $85(50.9)$ & 1491.85 (209.320) \\
\hline$P$ value & & 0.110 & 0.19 \\
\hline \multicolumn{4}{|l|}{ Occupation } \\
\hline Trading & 74 & $37(50.0)$ & $1407.78(1349.310)$ \\
\hline Civil servants & 63 & $29(46.0)$ & $1592.24(1622.752)$ \\
\hline Farming & 20 & $10(50.0)$ & $2280.80(1675.544)$ \\
\hline Students & 57 & $33(57.9)$ & 2064.94 (1739.525) \\
\hline Artisans & 42 & $24(57.1)$ & $1748.17(2126.970)$ \\
\hline Others & 44 & $32(24.2)$ & $2132.97(2328.753)$ \\
\hline$P$ value & & 0.115 & 0.481 \\
\hline \multicolumn{4}{|l|}{ Education } \\
\hline No Formal Education & 37 & $27(73.0)$ & $2626.96(2442.195)$ \\
\hline Primary & 110 & $60(54.5)$ & 1894.52 (1775.649) \\
\hline Secondary & 109 & $58(53.2)$ & 1419.16 (1414.614) \\
\hline Tertiary & 44 & $20(45.5)$ & $1625.75(1857.351)$ \\
\hline$P$ value & & 0.086 & 0.38 \\
\hline \multicolumn{4}{|l|}{ Hospital visited } \\
\hline Adeoyo State Hospital & 196 & $106(54.1)$ & $2207.38(2045.230)$ \\
\hline Oni Memorial Hospital & 104 & $59(56.7)$ & $1109.20(1048.542)$ \\
\hline$P$ value & & 0.661 & $<0.0001$ \\
\hline \multicolumn{4}{|c|}{ Travel to rural area/village last month } \\
\hline Yes & 125 & $93(74.4)$ & $2367.51(2098.600)$ \\
\hline No & 175 & $72(41.1)$ & $1100.65(1050.686)$ \\
\hline$P$ value & & $<0.0001$ & $<0.0001$ \\
\hline Total & 300 & $165(55.0)$ & 1814.70 (1829.117) \\
\hline
\end{tabular}

Table 2 details the prevalence and parasite density of $P$. falciparum infection stratified by genotype and blood group. Genotype $\mathrm{HbAA}$ had the highest malaria prevalence of $62.6 \%$ and mean (S.D) parasite density of 1937.33 (1627.828) parasite/ $\mu \mathrm{L}$ of blood while genotype $\mathrm{HbSS}$ had the least malaria prevalence of $12.5 \%$. The result was statistically significant $(P<0.05)$. Also, while blood group 0 significantly $(P<0.05)$ had the highest prevalence of $68.8 \%$ and blood group $A B$ had the least malaria prevalence (Table 2). 
Table 2: Prevalence and density of Plasmodium falciparum infection stratified by genotype and blood group

\begin{tabular}{|llll|}
\hline Variables & Number of subjects & Number positive $(\%)$ & Mean $( \pm$ S.D) Parasite Density (parasite/ $\mu \mathrm{L}$ of blood) \\
Genotype & & & \\
AA & 147 & $92(62.6)$ & $1937.33(1627.828)$ \\
AS & 133 & $67(50.4)$ & $1713.76(2113.703)$ \\
AC & 9 & $4(44.4)$ & $1256.75(1488.377)$ \\
SS & 8 & $1(12.5)$ & - \\
SC & 3 & $1(33.3)$ & - \\
P value & & 0.023 & 0.776 \\
Blood group & & & $2118.30(1862.318)$ \\
A & 97 & $54(55.7)$ & $1240.20(1244.996)$ \\
B & 11 & $5(45.5)$ & $1768.14(3087.814)$ \\
AB & 48 & $7(14.6)$ & $1681.40(1729.292)$ \\
O & 144 & $99(68.8)$ & 0.477 \\
P value & & $<0.0001$ & $1814.70(1829.117)$ \\
\hline Total & 300 & $165(55.0)$ & \\
\hline
\end{tabular}

Table 3 presents environmental variables and their association with malaria infection prevalence and density. Presence of stream and distance from stream are significantly $(P<0.05)$ related to malaria infection prevalence. Those who had open water or stream and are within the distance of $\leq 1 \mathrm{Km}$ are more likely to have malaria infection. Similarly, sleeping under the mosquito net the previous night significantly $(P<0.05)$ reduced malaria infection (Table 4).

Table 3: Prevalence and density of Plasmodium falciparum infection stratified by environmental variables 


\begin{tabular}{|c|c|c|c|}
\hline Variables & $\begin{array}{l}\text { Number of } \\
\text { subjects }\end{array}$ & $\begin{array}{l}\text { Number positive } \\
(\%)\end{array}$ & $\begin{array}{l}\text { Mean ( } \pm \text { S.D) Parasite Density (parasite/ } \mu \mathrm{L} \text { of } \\
\text { blood) }\end{array}$ \\
\hline \multicolumn{4}{|l|}{ Presence of Vegetation } \\
\hline Yes & 128 & $75(58.6)$ & 1909.12 (1884.169) \\
\hline No & 172 & $90(52.3)$ & 1736.01 (1788.719) \\
\hline$P$ value & & 0.280 & 0.547 \\
\hline \multicolumn{4}{|l|}{ Distance from vegetation } \\
\hline$\leq 1 \mathrm{Km}$ & 61 & $39(63.9)$ & 1793.31 (1750.687) \\
\hline$>1 \mathrm{Km}$ & 67 & $36(53.7)$ & 2034.58 (2036.458) \\
\hline No Vegetation & 172 & $90(52.3)$ & 1736.01 (1788.719) \\
\hline$P$ value & & 0.285 & 0.710 \\
\hline \multicolumn{4}{|l|}{$\begin{array}{l}\text { Presence of open } \\
\text { water/stream }\end{array}$} \\
\hline Vec & 187 & $91(48.7)$ & 1784.27 (1955.472) \\
\hline No & 113 & $74(65.5)$ & $1852.11(1673.128)$ \\
\hline \multicolumn{4}{|l|}{$P$ value } \\
\hline $\begin{array}{l}\text { Distance from open } \\
\text { water/Stream }\end{array}$ & 75 & $48(64.0)$ & 1576.69 (1938.798) \\
\hline$\leq 1 \mathrm{Km}$ & 112 & $43(38.4)$ & 2016.00 (1970.623) \\
\hline$>1 \mathrm{Km}$ & 113 & $74(65.5)$ & $1852.11(1673.128)$ \\
\hline No open water/Stream & & $<0.0001$ & 0.508 \\
\hline \multicolumn{4}{|l|}{$P$ value } \\
\hline Environmental Sanitation & 188 & $97(51.6)$ & 1783.96 (1760.957) \\
\hline Yes & 112 & $68(60.7)$ & 1858.54 (1934.656) \\
\hline No & & 0.125 & 0.797 \\
\hline \multicolumn{4}{|l|}{$P$ value } \\
\hline Total & 300 & $165(55.0)$ & $1814.70(1829.117)$ \\
\hline
\end{tabular}

Table 4: Prevalence and density of Plasmodium falciparum infection stratified by ownership and use of mosquito nets 


\begin{tabular}{|c|c|c|c|}
\hline Variables & $\begin{array}{l}\text { Number of } \\
\text { subjects }\end{array}$ & $\begin{array}{l}\text { Number positive } \\
\text { (\%) }\end{array}$ & $\begin{array}{l}\text { Mean ( } \pm S . D \text { ) parasite density (parasite/ } \mu \mathrm{L} \text { of } \\
\text { blood) }\end{array}$ \\
\hline \multicolumn{4}{|l|}{ Own mosquito net } \\
\hline Yes & 215 & $129(60.0)$ & 1904.27 (1954.169) \\
\hline No & 85 & $36(42.4)$ & $1493.72(1255.188)$ \\
\hline$P$ value & & 0.006 & 0.235 \\
\hline \multicolumn{4}{|l|}{$\begin{array}{l}\text { Slept under mosquito net last } \\
\text { night }\end{array}$} \\
\hline Yes & 41 & $19(46.3)$ & 1623.58 (1547.594) \\
\hline $\mathrm{No}$ & 175 & $111(63.4)$ & 1942.21 (2011.998) \\
\hline TNO & 84 & $35(41.7)$ & 1514.06 (1267.482) \\
\hline$P$ value & & 0.002 & 0.432 \\
\hline $\begin{array}{l}\text { Reason for not sleeping under } \\
\text { bed net }\end{array}$ & 88 & $54(61.4)$ & 2448.94 (2189.184) \\
\hline Causes heat & 41 & $21(51.2)$ & 1129.05 (1256.053) \\
\hline Disfigure room & 40 & $30(75.0)$ & $1340.40(1689.851)$ \\
\hline Not effective & 6 & $2(33.3)$ & 2015.50 (1738.776) \\
\hline Use alternative & 125 & $58(68.8)$ & $1710.84(1557.363)$ \\
\hline No mosquito net & & 0.001 & 0.018 \\
\hline$P$ value & & & \\
\hline Total & 300 & $165(55.0)$ & 1814.70 (1829.117) \\
\hline
\end{tabular}

Additionally, the results of the binary logistic regression model analysis showed the risk factors associated with malaria infection (Table 5). Being age group 6-10, having blood group 0 , presence of open water or stream, distance from open water or stream and travel to rural area or village the previous month were observed to be associated with malaria infection prevalence.

Table 5: Binary logistic regression model for crude odd ratio (ORs) of factors associated with prevalence of malaria infection 


\begin{tabular}{|c|c|c|}
\hline Variables & Crude Odd Ratio, OR (95\% Cl) & Pvalue \\
\hline \multicolumn{3}{|l|}{ Age group } \\
\hline$\leq 5$ & $0.133(0.008-2.370)$ & 0.170 \\
\hline $6-10$ & $0.066(0.007-0.635)$ & 0.019 \\
\hline $11-20$ & $0.494(0.093-2.620)$ & 0.407 \\
\hline $21-30$ & $0.872(0.273-2.789)$ & 0.818 \\
\hline $31-40$ & $1.118(0.302-4.129)$ & 0.868 \\
\hline $41-50$ & $1.111(0.326-3.783)$ & 0.866 \\
\hline$>50$ & 1 & 0.143 \\
\hline \multicolumn{3}{|l|}{ Gender } \\
\hline Male & $1.806(0.919-3.548)$ & 0.086 \\
\hline Female & 1 & \\
\hline \multicolumn{3}{|l|}{ Occupation } \\
\hline Trading & $0.907(0.175-4.711)$ & 0.908 \\
\hline Civil servants & $1.491(0.291-7.650)$ & 0.632 \\
\hline Farming & $1.470(0.197-10.952)$ & 0.707 \\
\hline Students & $7.105(0.740-68.173)$ & 0.089 \\
\hline Artisans & $1.187(0.192-7.320)$ & 0.853 \\
\hline Others & 1 & 0.268 \\
\hline \multicolumn{3}{|l|}{ Education } \\
\hline No Formal Education & $2.156(0.178-26.060)$ & 0.546 \\
\hline Primary & $1.166(0.331-4.103)$ & 0.811 \\
\hline Secondary & $1.123(0.379-3.333)$ & 0.834 \\
\hline Tertiary & 1 & 0.947 \\
\hline \multicolumn{3}{|l|}{ Genotype } \\
\hline$A A$ & $0.747(0.037-14.898)$ & 0.849 \\
\hline AS & $0.864(0.045-16.457)$ & 0.923 \\
\hline$A C$ & $0.391(0.013-11.351)$ & 0.585 \\
\hline SS & $7.369(0.152-382.626)$ & 0.322 \\
\hline SC & 1 & 0.456 \\
\hline \multicolumn{3}{|l|}{ Blood group } \\
\hline A & $1.884(0.960-3.699)$ & 0.066 \\
\hline B & $3.094(0.640-14.966)$ & 0.160 \\
\hline$A B$ & $15.404(5.248-45.214)$ & 0.000 \\
\hline 0 & 1 & 0.000 \\
\hline Presence of Vegetatio & & \\
\hline
\end{tabular}

Page 10/16 


\begin{tabular}{|lcc|} 
Yes & $1.264(0.474-3.376)$ & 0.640 \\
No & 1 & \\
Distance from vegetation & & \\
$\leq 1 \mathrm{Km}$ & $0.436(0.152-1.250)$ & 0.122 \\
$>1 \mathrm{Km}$ & 1 & \\
\hline & & \\
\hline
\end{tabular}

Table 5 (Continue): Binary logistic regression model for crude odd ratio of factors associated with prevalence of malaria infection

\begin{tabular}{|c|c|c|}
\hline Variables & Crude Odd Ratio, OR (95\% Cl) & P.value \\
\hline \multicolumn{3}{|c|}{ Presence of stream } \\
\hline Yes & $0.225(0.103-0.492)$ & 0.001 \\
\hline No & 1 & \\
\hline \multicolumn{3}{|c|}{ Distance from Stream } \\
\hline$\leq 1 \mathrm{Km}$ & $0.283(0.122-0.654)$ & 0.003 \\
\hline$>1 \mathrm{Km}$ & 1 & \\
\hline \multicolumn{3}{|c|}{ Environmental Sanitation } \\
\hline Yes & $0.612(0.320-1.169)$ & 0.137 \\
\hline No & 1 & \\
\hline \multicolumn{3}{|c|}{ Have mosquito net } \\
\hline Yes & $14.742(3.121-69.630)$ & 0.001 \\
\hline No & 1 & \\
\hline \multicolumn{3}{|c|}{ Slept under mosquito net last night } \\
\hline Yes & $0.349(0.115-1.062)$ & 0.064 \\
\hline No & 1 & \\
\hline \multicolumn{3}{|c|}{ Travel to rural area last month } \\
\hline Yes & $4.689(2.430-9.049)$ & 0.000 \\
\hline No & 1 & \\
\hline
\end{tabular}

\section{Discussion}

The result of this study is a strong evidence that malaria is still highly prevalent in many urban communities including Ibadan South West Local Government Area of Oyo State, Nigeria. The high prevalence of $55 \%$ with mean (S.D) parasite density of 1814.70 (1829.117) parasite/ $\mu \mathrm{L}$ of blood is an indication that lbadan is a high-risk area for malaria transmission since it falls within Nigeria malaria risk map estimates of less than $20 \%$ in certain zone to more than $70 \%$ in other zones [15]. This is supported by other studies reported from Ibadan $[8,16,17]$. Similarly, the current prevalence of $55 \%$ from urban area of Ibadan is lower than those reported from many rural areas. This agrees with the reports of Wang et al. [18] and Baragatti et al. [19] who reported lower malaria prevalence of $24.1 \%$ and $26.1 \%$ respectively in urban areas. In some rural settings, prevalence as high as $74 \%$ and $71.4 \%$ have been reported $[9,20]$. Thus, while evidence abound on malaria prevalence in urban areas, prevalence is 
generally lower than rural areas $[11,21]$. This lower malaria prevalence in urban areas could be as a result of better access to health facilities, well-designed houses that can protect against mosquito vectors, improved basic amenities and reduced mosquito breeding sites [22].

Our findings on age specific pattern of malaria prevalence and mean parasite density showed that age group $\leq 5$ years had highest malaria infection. Similar findings have been reported in previous studies [23,24]. In fact, World Health Organization have emphasized this fact that children age five years and below are the most vulnerable group of people particularly in Africa [3]. This can be attributed to the gradual loss of maternal immunity coupled with low level of acquired immunity among children compared to adults. Thus, as age and exposure increases, malaria infection decreases except among elderly ones and the immunocompromised. Additionally, the sex pattern of infection in this study showed that males had higher malaria prevalence and mean parasite density compared to their female colleagues. This is related and comparable to previous reports from other studies in malaria endemic areas [25,26]. This could be due to the fact that males usually get involve in outdoor activities, staying late until night outside, have lackadaisical attitude towards malaria prevention and farming which inadvertently expose them to high mosquito bites than females. Furthermore, those without formal education had infection that almost doubled those who attained tertiary education though there was no association. This is in line with previous studies which showed that people can be acquainted with the knowledge of malaria transmission, prevention and control irrespective of their educational status [27,28]. This is however in contrast to the report of Adedotun et al., [29], Eteng et al., [30] and Dawaki et al., [31] who noted that the level of education significantly influence the knowledge, attitude and practices of people which in turn can lead to reduced malaria infection. Similarly, those who travelled to rural area or village in this study area had higher malaria prevalence and density. This is corroborated by studies conducted in malaria endemic zones [19,32]. Generally, people are at greater risk when they travel from urban areas to rural areas due to the high number of mosquito vector present in rural areas. This is further aggravated by the low immunity of urban dwellers [33]. Chemoprophylactic drugs are recommended for use before and during such visit to rural areas in order to prevent development of malaria infection.

Furthermore, our findings showed that genetic factors such as genotype and blood group also influenced malaria parasite distribution in this study areas. Having blood group $\mathrm{O}$ is significantly associated with higher malaria infection. This is corroborated by Akhigbe et al., [34] and Afoakwah et al., [35] who recorded higher malaria prevalence for blood group 0. Another study suggested that $A B O$ blood group does not hinder the development of uncomplicated falciparum malaria but severe malaria [36]. This variation could be due to the different geographical regions [37]. In the same vein, haemoglobin AA is significantly associated with malaria infection in this study. This is consistent with previous findings [38,39] but inconsistent with the report of Suchdev et al., [40] who finds no significant association between genotype AA, AS and SS in Kenya.

Finally, the binary logistic regression analysis showed that age group 6-10, presence of streams, distance from streams within $\leq 1 \mathrm{Km}$ and travel to rural area were the major risk factors which often increase the odds of malaria infection in this study area. These findings is in agreement with previous studies in Nigeria and other malaria endemic regions [19,32,41,24].

\section{Conclusion}

Apparently, malaria is endemic in Ibadan city and this is a glaring evidence indicating malaria as a public health challenge even in urban areas. Major risk factor influencing transmission include age, presence of stream within $\leq 1 \mathrm{Km}$ from home and most importantly travel to rural areas. Health education on mosquito prevention and use of chemoprophylaxis before and during travel to rural areas is important and recommended.

\section{Limitations}

Although this study provided relevant epidemiological findings on the prevalence, density and major risk factors affecting transmission in the urban city of Ibadan, the sample size was not large enough to accommodate likely errors due to sampling.

\section{Abbreviations}

C.I: Confidence Interval; Km: Kilometer; OR: Odd Ratio; S.D: Standard Deviation; WHO: World Health Organization.

Page $12 / 16$ 


\section{Declarations}

\section{Competing interests}

The authors declare no competing interests.

\section{Authors' contributions}

O.B.A. conceived, designed, performed the statistical analysis and drafted the original manuscript, Z.S.Y proofread and approved the final manuscript, F.H.M.T proofread and corrected manuscript, lyabo Adepeju Simon-Oke proofread and corrected manuscript, C.F. carried out the field work and performed the laboratory experiments.

\section{Funding}

No funding was received for this research.

\section{Availability of data and materials}

The data of this current study is available from the corresponding author upon reasonable request.

\section{Ethical approval and consent to participate}

The protocol for this study was approved by Ondo State Ministry of Health (protocol number OSHREC/09/04/2018/046) the Ethical Review Committee, Federal University of Technology, Akure, Nigeria. Informed consent that were written were obtained from each adult subject. However, for children, their caregiver or guardians provided the informed consent.

\section{Consent for publication}

Not applicable

\section{Acknowledgements}

We sincerely appreciate all who participated in this study for their support.

\section{References}

1. World Health Organization. Microscopy for the detection, identification and quantification of malaria parasites on stained thick and thin blood films in research settings (version 1.0): procedure: methods manual.: World Health Organization; 2015. p. 32.

2. Besansky NJ, Hill CA, Costantini C. No accounting for taste: Host preference in malaria vectors. Trends Parasito/ 2004;20: 249-251.

3. World Health Organization. World malaria report 2018. Geneva: World Health Organization; 2018. https ://www.who.int/malaria/publicatio ns/world -malar ia-report-2018/en/. Accessed Feb 62020.

4. Abeysinghe, Rabindra. Outcomes from the evidence review group on Plasmodium knowlesi. In: Present. Malar. Policy Advis. Comm. Meet. 22-24 March 2017, Geneva.

5. Gething, P. W., Elyazar, I. R., Moyes, C. L., Smith, D. L., Battle, K. E., Guerra, C. A., et al. (2012). A long neglected world malaria map: Plasmodium vivax endemicity in 2010. PLoS Negl. Trop Dis. 2012; 6:e1814. doi: 10.1371/journal.pntd. 0001814.

6. WHO. World Malaria Report 2017. Geneva: World Health Organization; 2017. https://doi.org/10.1071/EC12504. Accessed 6 May 2020.

7. FMOH. National Malaria Control Programme, Abuja, Nigeria. Strategic Plan 2009-2013. A Road Map for Malaria Control in Nigeria. Draft 16 June 2008.

http://www.nationalplanningcycles.org/sites/default/fles/country_docs/Nigeria/nigeria_draft_malaria_strategic_plan_20092013. 
8. Okonko IO, Donbraye-Emmanuel OOB, Donbraye E, Abubakar MJ, Fowotade A, Fadeyi A, Babalola ET, Ojezele MO, Adeyi AO. Malaria parasitaemia among patients in Ibadan, Southwestern Nigeria. J. Appl. Biosci. 2010; 29:1774-1780.

9. Awosolu, O.B., David, M.C., Lawal, A.O. \& Ikuesan, F.A. Pattern of Malaria Parasitaemia and Genotype among Residents of Orita Obele, Akure South Local Government Area of Ondo State, Nigeria. South Asian Journal of Parasitology 2019; 3(2) 1-5, Article no.SAJP.52485.

10. Govoetchan, R., Gnanguenon, V., Azondékon, R. et al. Evidence for perennial malaria in rural and urban areas under the Sudanian climate of Kandi, Northeastern Benin. Parasites Vectors. 2014; 7, 79. https://doi.org/10.1186/1756-3305-7-79.

11. Anumudu Cl, Adepoju A, Adeniran M, Adeoye O, Kassim A, Oyewole I, Nwuba RI. Malaria prevalence and treatment seeking behaviour of young Nigerian adults. Ann. Afr. Med. 2006; 15:82-88.

12. Olusegun-Joseph, T.S., Oboh, M.A., Godwin O. Ovioma, G.O., Fagbohun, I.K.,Okorafor, U., Aina, D.D. Differential Prevalence of Malaria Infection in Rural and Urban Out-Patient Clinics in Lagos State, Nigeria. Pan African Journal of Life Sciences 2019; 2: 79-84.

13. Anumudu Cl, Okafor CMF, Ngwumohaike V, Afolabi KA, Nwuba RI, Nwagwu M. Epidemiological factors that promote the development of severe malaria anaemia in children in Ibadan. Afr. Health. Sci., 2007; 7 (2): 80-85.

14. Atroosh, W.M., Al-Mekhlaf, H.M., Al-Jasari, A., Sady, H., Al-Delaimy, A.K., Nasr, N.A, et al.. Genetic variation of pfhrp2 in Plasmodium falciparum isolates from Yemen and the performance of HRP2-based malaria rapid diagnostic test. Parasit Vectors. 2015; 8:388.

15. Onyiri N. Estimating malaria burden in Nigeria: a geostatistical modelling approach. Geospat Health. 2015; 10:306. doi:10.4081/gh.2015.306.

16. Okonko IO, Adejuwon OA, Okerentugba PO, Innocent-Adiele HC. Circulating Plasmodium falciparum and HIV $1 / 2$ as coinfections among blood donors in Ibadan, Southwestern Nigeria. Nature and Science. 2012;10(9):42-47.

17. Bello, F. A., \& Ayede, A. I. Prevalence of malaria parasitaemia and the use of malaria prevention measures in pregnant women in Ibadan, Nigeria. Annals of Ibadan postgraduate medicine, 2019; 17(2), 124-129.

18. Wang SJ, Lengeler C, Smith TA, et al. Rapid urban malaria appraisal (RUMA) I: epidemiology of urban malaria in Ouagadougou. Malar J. 2005; 4: 43.

19. Baragatti, M., Fournet, F., Henry, M. et al. Social and environmental malaria risk factors in urban areas of Ouagadougou, Burkina Faso. Malar J. 2009; 8, 13. https://doi.org/10.1186/1475-2875-8-13.

20. Woldearegai TG, Lalremruata A, Nguyen TT, Gmeiner M, Veletzky L, TazemdaKuitsouc GB, et al. Characterization of Plasmodium infections among inhabitants of rural areas in Gabon. Sci Rep. 2019; 9:9784.

21. Pond, B.S. Malaria indicator surveys demonstrate a markedly lower prevalence of malaria in large cities of sub-Saharan Africa. Malar J. 2013; 12, 313. https://doi.org/10.1186/1475-2875-12-313.

22. Klinkenberg, E., P.J. McCall, M. D. Wilson, F.P. Amerasinghe, and M. J. Donnelly. Impact of urban agriculture on malaria vectors in Accra, Ghana. Malar. J. 2008; 7: 151.

23. Hailemariam M, Gebre S. Trend analysis of malaria prevalence in Arsi Negelle health center, Southern Ethiopia. $J$ Infect Dis. 2015;7(1):1-6. https ://doi.org/10.5897/JIDI2014.0147.

24. Zgambo M, Mbakaya BC, Kalembo FW. Prevalence and factors associated with malaria parasitaemia in children under the age of five years in Malawi: A comparison study of the 2012 and 2014 Malaria Indicator Surveys (MISs). PLoS ONE 2017; 12(4): e0175537. https://doi.org/10.1371/journal.pone.0175537.

25. Gebretsadik D, Feleke DG, Fiseha M. Eight-year trend analysis of malaria prevalence in Kombolcha, South Wollo, northcentral Ethiopia: a retrospective study. Parasit Vectors. 2018; 11(1):55. https://doi. org/10.1186/s13071-018-2654-6.

26. Escobar, D.F., Lucchi, N.W., Abdallah, R. et al. Molecular and epidemiological characterization of imported malaria cases in Chile. Malar J. 2020; 19, 289. https://doi.org/10.1186/s12936-020-03353-y.

27. Muchena G, Dube B, Chikodzore R, Pasipamire J, Murugasampillay S, Mberikunashe J. A review of progress towards sub-national malaria elimination in Matabeleland South Province, Zimbabwe (2011-2015): a qualitative study. Malar J. 2018;17(1):146. doi: 10.1186/s12936- 018-2299-0. 
28. Dube, B., Mberikunashe, J., Dhliwayo, P., Tangwena, A., Shambira, G., Chimusoro, A., Gambinga, B. How far is the journey before malaria is knocked out malaria in Zimbabwe: Results of the malaria indicator survey 2016. Malaria Journal. 2019; 18(1), 171. doi:10.1186/s12936-019-2801-3.

29. Adedotun AA, Morenikeji OA, Odaibo AB. Knowledge, attitudes and practices about malaria in an urban community in southwestern Nigeria. J Vector Borne Dis. 2010; 47:155-9.

30. Eteng M, Mitchell S, Garba L, Ana O, Liman M, Cockcroft A, et al. Socioeconomic determinants of ownership and use of treated bed nets in Nigeria: results from a cross-sectional study in Cross River and Bauchi States in 2011. Malar J. 2014; 13:316. doi:10.1186/1475-2875-13-316.

31. Dawaki S, Al-Mekhlafi HM, Ithoi I, Ibrahim J, Atroosh WM, Abdulsalam AM, et al. Is Nigeria winning the battle against malaria? Prevalence, risk factors and KAP assessment among Hausa communities in Kano state. Malar J. 2016;15: 351.

32. Siri JG, Wilson ML, Murray S, Rosen DH, Vulule JM, Slutsker L, Lindblade KA: Significance of travel to rural areas as a risk factor for malarial anemia in an urban setting. Am J Trop Med Hyg 2010, 82:391-397.

33. Carme, B. Reducing the Risk of Malaria Acquisition by Urban Dwellers of Sub-Saharan Africa during Travel in MalariaEndemic Areas, The Journal of Infectious Diseases, Volume 170, Issue 1, July 1994, Pages 257258, https://doi.org/10.1093/infdis/170.1.257.

34. Akhigbe R. E., Ige S. F., Adegunlola G. J., Adewumi M. O., Azeez, O. M. Malaria, Haemoglobin Genotypes and ABO Blood Groups in Ogbomoso, Nigeria. Inter. J. of Trop. Med. 2011;6 (4): 73-76.

35. Afoakwah R, Aubyn E, Prah J, Nwaefuna EK, Boampong JN. Relative susceptibilities of ABO blood groups to Plasmodium falciparum malaria in Ghana. Adv Hematol. 2016; 5368793.

36. Degarege A, Gebrezgi MT, Beck-Sague CM, Wahlgren M, de Mattos LC, Madhivanan P. Effect of ABO blood group on asymptomatic, uncomplicated and placental Plasmodium falciparum infection: systematic review and meta-analysis. $B M C$ Infect Dis. 2019;19(1):86.

37. Manjurano A, Sepulveda N, Nadjm B, Mtove G, Wangai H, Maxwell C, Olomi R, Reyburn H, Riley EM, Drakeley CJ, et al. African glucose-6-phosphate dehydrogenase alleles associated with protection from severe malaria in heterozygous females in Tanzania. PLoS Genet. 2015;11(2):e1004960.

38. Komba AN, Makani J, Sadarangani M, Ajala-Agbo T, Berkley JA, Newton CR, Marsh K, Williams TN. Malaria as a cause of morbidity and mortality in children with homozygous sickle cell disease on the coast of Kenya. Clin Infect Dis. 2009;49(2):216-22.

39. McAuley CF, Webb C, Makani J, Macharia A, Uyoga S, Opi DH, Ndila C, Ngatia A, Scott JA, Marsh K, et al. High mortality from Plasmodium falciparum malaria in children living with sickle cell anemia on the coast of Kenya. Blood. 2010;116(10):1663-8.

40. Suchdev PS, Ruth LJ, Earley M, Macharia A, Williams TN. The burden and consequences of inherited blood disorders among young children in western Kenya. Matern Child Nutr. 2014;10(1):135-44.

41. Ceesay SJ, Bojang KA, Nwakanma D, Conway DJ, Koita OA, Doumbia SO, Ndiaye D, Coulibaly TF, Diakité M, Traoré SF, Coulibaly M, Ndiaye JL, Sarr O, Gaye O, Konaté L, Sy N, Faye B, Faye O, Sogoba N, Jawara M, Dao A, Poudiougou B, Diawara S, Okebe J, Sangaré L, Abubakar I, Sissako A, Diarra A, Kéita M, Kandeh B, Long CA, Fairhurst RM, Duraisingh M, Perry R, Muskavitch MA, Valim C, Volkman SK, Wirth DF, Krogstad DJ: Sahel, savana, riverine and urban malaria in West Africa: Similar control policies with different outcomes. Acta Trop 2012, 121:166-174.

\section{Figures}



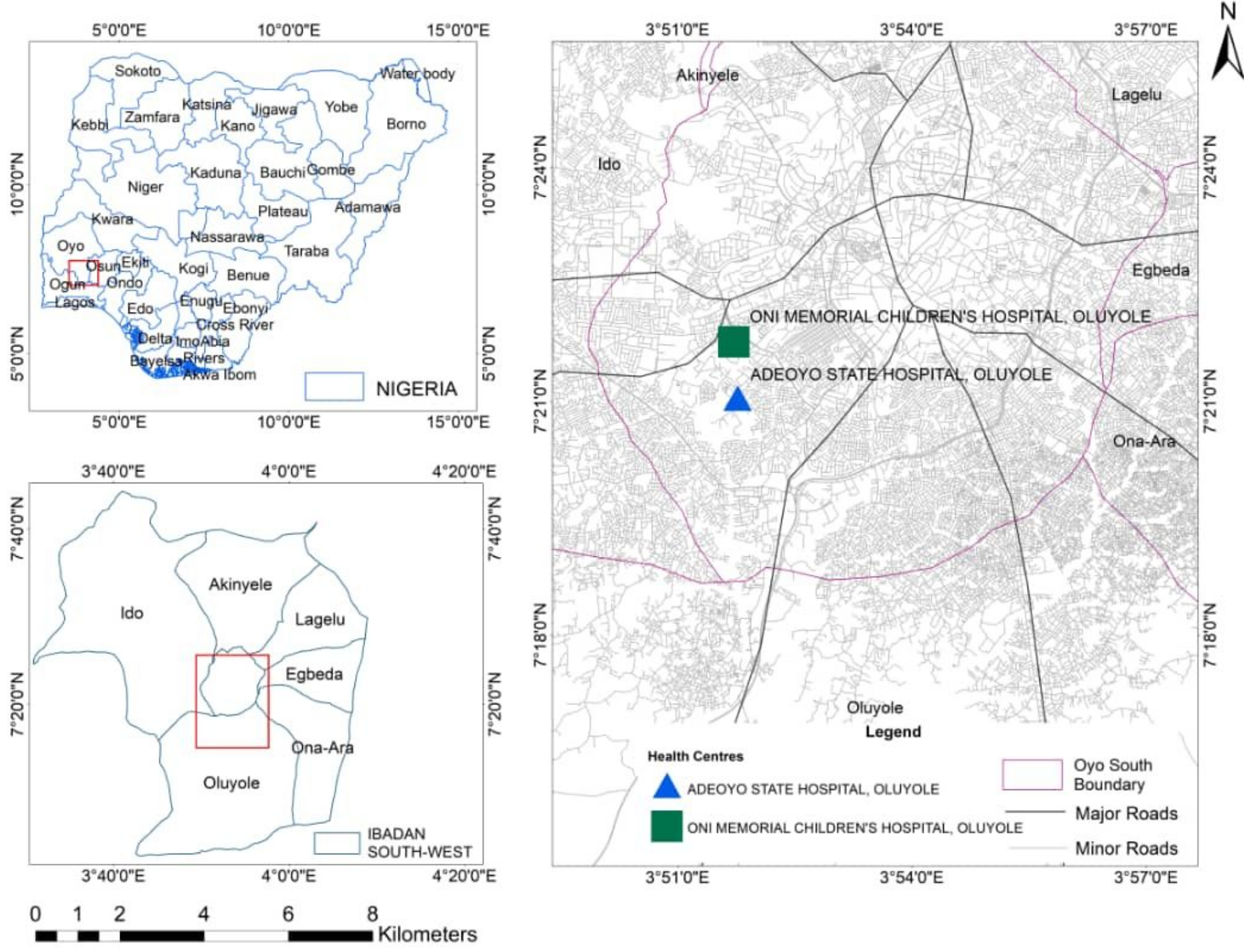

\section{Figure 1}

Map of Adeoyo State Hospital and Oni Memorial Children's Hospital in Ibadan, Nigeria 